\title{
DAMPAK VIBRASI MEKANIK TERHADAP KONSUMSI LISTRIK MOTOR INDUKSI POMPA AIR PENDINGIN
}

\author{
Conny K. Wachjoe ${ }^{1}$, Metius Zingiber Sianturi ${ }^{2}$ \\ Jurusan Teknik Konversi Energi, Politeknik Negeri Bandung \\ email: cwachjoe@gmail.com
}

\begin{abstract}
Abstrak
Pompa air pendingin merupakan komponen pendukung fital pada pembangkit listrik tenaga air (PLTA) sehingga pompa air pendingin harus bekerja optimal setiap saat. Penggerak pompa air pendingin dihasilkan melalui motor listrik. Pada sistem pompa air dengan kapasitas besar besar, motor dan pompa air terhubung dengan poros kopling agar selalu lurus (align) antar ke duanya. Keausan pada bearing dan dudukan motor dan pompa akibat putaran akan meningkatkan vibrasi mekanik. Energi mekanik yang dibangkitkan motor listrik ke pompa air dipengaruhi oleh tingkat vibrasi mekanik yang timbul. Dampak vibrasi mekanik terhadap kinerja motor listrik kapasitas $150 \mathrm{~kW}$ dicermati melalui studi kasus yang dilakukan pada Unit I PLTA Cirata. Metode pengamatan dilakukan melalui perangkat vibration analyzer terpasang dibandingkan dengan standar vibrasi mekanik ISO 10816-3 [3]. Dampak vibrasi mekanik terhadap umur mesin dan konsumsi energi listrik didekati berdasarkan pendekatan empirik pada kondisi misalignment antara motor dan pompa air [1]. Dampak vibrasi mekanik terhadap umur mesin menunjukkan bahwa motor listrik masih dapat dioperasikan selama $15 \%$ dari umur mesin normal pada kondisi vibrasi mekanik maksimum dengan total offset sebsesar $1.0 \mathrm{~mm} / \mathrm{s}$, Sedangkan dampak vibrasi mekanik terhadap konsumsi energi motor listrik meningkat sebesar 6,92\% pada konsumsi energi sebesar $122 \mathrm{~kW}$ pada total offset vibrasi mekanik sebesar $1,61 \mathrm{~mm} / \mathrm{s}$.
\end{abstract}

Kata kunci: misalignment, vibrasi mekanik, umur mesin, dan konsumsi listrik

\section{PENDAHULUAN}

PLTA Cirata merupakan salah satu PLTA yang sangat penting dalam mendukung beban puncak sistem kelistrikan Jawa-Bali, dan merupakan PLTA terbesar di Indonesia dengan kapasitas pembangkitan sebesar 1008 MW. Operasi PLTA sangat bergantung kepada ketersediaan air dan perangkat- sistem pembangkitan tenaga listriknya. Perangkat pendukung PLTA harus tetap dalam kondisi optimal agar PLTA dapat menyalurkan tenaga listrik secara maksimal. Salah satu perangkat pendukung utama, seperti Cooling Water Pump (CWP) harus beroperasi dengan baik untuk mendinginkan oli pelumas (Thrust Bearing Oil Cooler, Turbine Guide Bearing Oil Cooler, Governor Oil Cooler), dan Generator Air Cooler. Pompa pada CWP dengan kapasitas sebesar $150 \mathrm{~kW}$ adalah tipe pompa sentrifugal yang dihubungkan dengan motor listrik sebagai penggeraknya. Pengoperasian CWP dilakukan bersamaan dengan program perawatan yang telah direncanakan.
Perawatan rutin dan perawatan khusus (predictive maintenance dan proactive maintenance) bertujuan untuk dapat mengantisipasi operasi optimal sistem PLTA.

CWP pada PLTA Cirata dirancang dengan menggunakan kopling fleksibel antara motor dengan pompanya (Gambar 1), sehingga dapat meredam bila terjadi vibrasi mekanik.

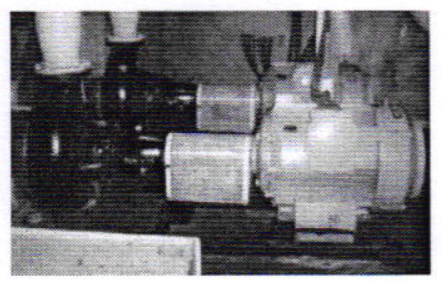

Gambar 1. CWP pada Unit I PLTA Cirata 
Vibrasi pada motor dapat di akibatkan oleh beberapa hal seperti misalignmet dan looseness. misalignment, yaitu ketika dua poros yang dihubungkan tidak lagi berada dalam dalam satu sumbu, sehingga akan menimbulkan vibrasi yang lebih besar dari vibrasi normal pada motor. Untuk itu akan dibahas bagaimana hubungan antara, vibrasi mekanik dan konsumsi energi listrik pada motor induksi pada CWP.

\section{METODOLOGI}

Secara visual vibrasi mekanik adalah gerakan bolak balik dari suatu mesin, yang dapat dirasa dengan tangan atau oleh seluruh tubuh kita, yang dikenal sebagai getaran. Sebagai ilustrasi (Gambar 2), sebuah piringan yang sedang berputar pada tepinya ditempeli sebuah pemberat hingga unbalance ${ }^{[5]}$. Maka timbullah gaya sentripetal oleh pemberat tersebut, yang berusaha menarik piringan itu keluar dari perputarannya secara radial.

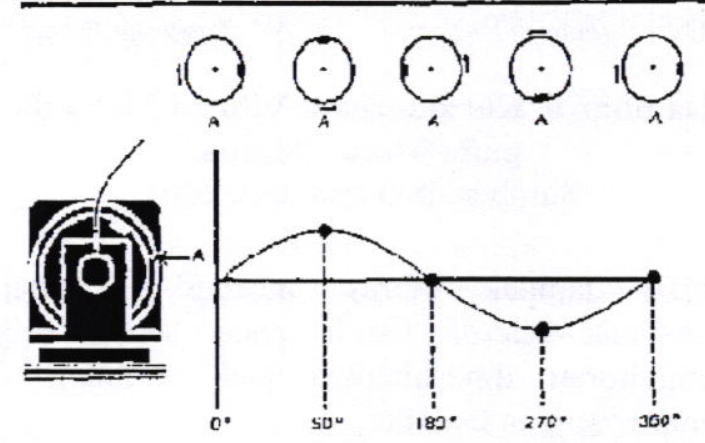

\section{Gambar 2. Ilustrasi Vibrasi dengan Piringan Hitam}

(Sumber: PT PLN, Jasa diklat, 2011)

Parameter vibrasi mekanik dibedakan dalam 3 kategori yaitu jarak vibrasi, kecepatan vibrasi dan percepatan vibrasi ${ }^{[2]}$, Displacement (Jarak vibrasi) adalah jarak yang ditempuh oleh gerakan bolakbalik (getaran) pada suatu periode waktu tertentu. Hal ini jika menurut Gambar 2 adalah jarak pergeseran titik putar piringan karena gaya sentripetal, dalam pengukuran vibrasi kita hanya dapat mengukur peak to peak displacement, yaitu jarak dari positif maksimum ke negatif maksimum atau sama dengan $2 \times \mathrm{A}$.

Velocity (Kecepatan vibrasi) adalah kecepatan gerakan bolak balik pada suatu periode waktu tertentu. Kecepatan ini selalu berubah sepanjang jarak yang ditempuhnya, dimana pada posisi positif maksimum dan negatif maksimum kecepatan adalah nol. Pada posisi gerakan melewati daerah netral kecepatan adalah maksimum. Dalam pengukuran vibrasi kita hanya dapat mengukur kecepatan maksimum atau disebut peak velocity.

Acceleration (Percepatan vibrasi) adalah percepatan gerak bolak balik pada suatu periode waktu tertentu. Percepatan selalu berubah sepanjang jarak yang ditempuhnya, dimana maksimum pada saat displacement mencapai positif maksimum atau mendekati negatif maksimum. Dalam pengukuran vibrasi kita hanya dapat mengukur percepatan vibrasi maksimum atau disebut peak acceleration.

Berdasarkan Standard Internasional ISO 10816-3, 2003 $3^{[3]}$, dampak kecepatan vibrasi terhadap kelayakan operasi motor listrik diperlihatkan pada Gambar 3.

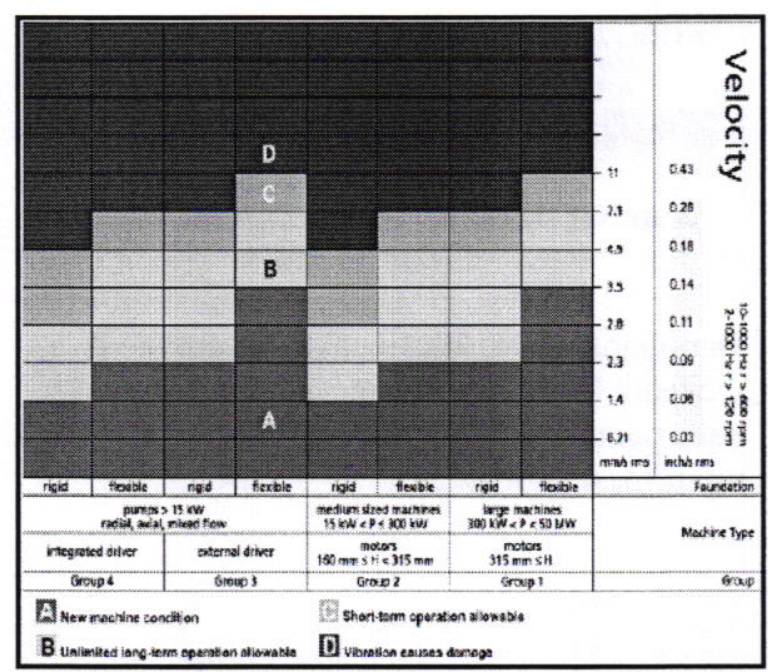

Gambar 3. Dampak Kecepatan Vibrasi pada Motor

Salah satu penyebab terjadinya vibrasi mekanik adalah misalignment, yaitu kondisi dimana terjadi penyimpangan pada titik pusat antara dua poros yang dihubungkan (dua poros terletak tidak pada satu sumbu). Misalignment terdiri atas tiga jenis yaitu Offset/parallel misalignment, Angular misalignment., \& Combination misalignment ${ }^{[4]}$. Offset/parallel misalignment terjadi jika garis sumbu dua poros berputar sejajar tetapi tidak berada dalam satu garis sumbu. Kondisi ini terjadi akibat kedua garis tengah antara poros tidak dalam keadaan satu sumbu. Angular misalignment terjadi jika poros pada kopling tidak segaris dan berpotongan membentuk sudut tertentu. 
Sedangkan Combination misalignment terjadi jika dua poros berputar tidak berhadapan.

Menurut kajian yang telah dilakukan oleh PRÜFTECHNIK ${ }^{[1]}$ mengenai dampak misalignment terhadap umur mesin dan konsumsi energi listrik, menjelaskan bahwa umur mesin akan berkurang sejalan dengan meningkatnya vibrasi mekanik (Gambar 4). Demikian pula konsumsi energi listrik meningkat dengan kenaikan vibrasi mekanik (Gambar 5).

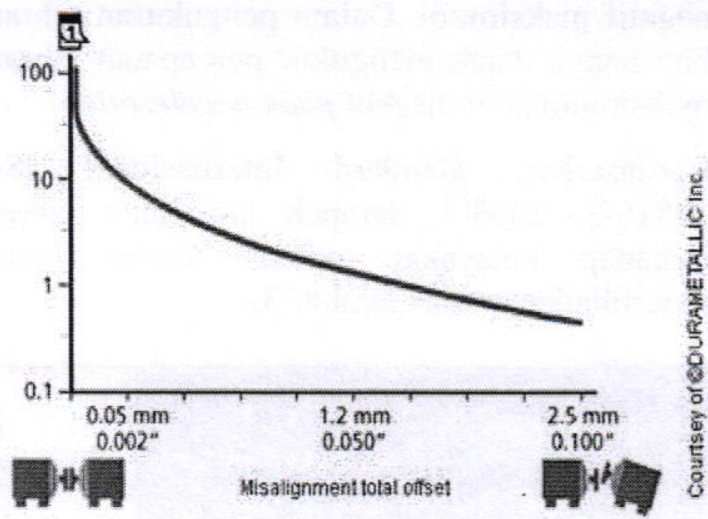

\section{Gambar 4. Dampak Misalignment pada} Umur Mesin

Dari Gambar 4 terlihat bahwa besarnya vibrasi mekanik lebih dari 2,5 mm akan berdampak pada penurunan umur mesin hingga $0,5 \%$ dari umur mesin normal.

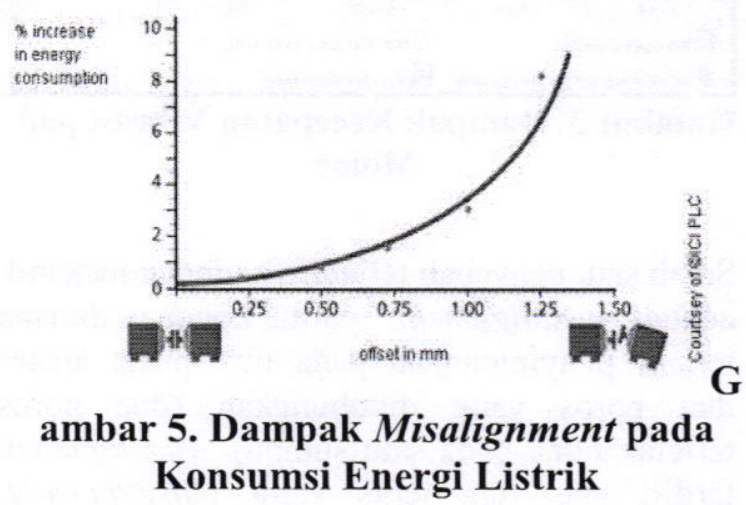

Gambar 5 menunujukkan bahwa peningkatan vibrasi mekanik sampai dengan $1,5 \mathrm{~mm}$ akan meningkatnya konsumsi energi listrik hingga $10 \%$ sebagai rugi-rugi dalam menkompensasi vibrasi tersebut.

\section{HASIL DAN PEMBAHASAN}

Pengamatan dampak vibrasi mekanik pada motor CWP dicermati berdasarkan hasil pengukuran yang dilakukan pada bulan Agustus 2011. Adapun titik pengukuran dilakukan sesuai dengan yang digunakan oleh PLN (ISO 10816-3, 2003), sebagaimana diperlihatkan pada Gambar 6.

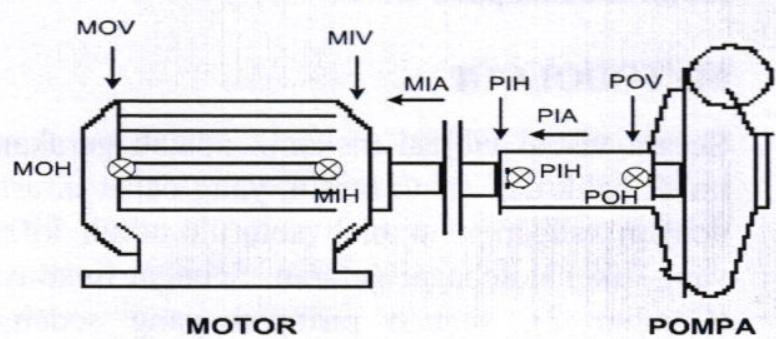

Keterangan:

$\begin{array}{llll}\text { MOH } & \text { Motor Out Horizontal } & \text { PIH } & \text { Pump In Horizontal } \\ \text { MOV } & \text { Motor Out vertical } & \text { PIV } & \text { Pump in vertical } \\ \text { MIA } & \text { Motor In Axial } & \text { PIA } & \text { Pump In Axial } \\ \text { MIH } & \text { Motor In Horizontal } & \text { POH } & \text { Pump Out horizontal } \\ \text { MIV } & \text { Motor In Vertical } & \text { POV } & \text { Pump Out Vetical }\end{array}$

\section{Gambar 6. Karakteristik Vibrasi Mekanik pada Motor Pompa}

Sumber: ISO 10816-3, 2003

Profil dampak vibrasi mekanik terhadap konsumsi energi listrik pada setiap titik pengukuran diperlihatkan pada Gambar 7 sampai dengan Gambar 11.

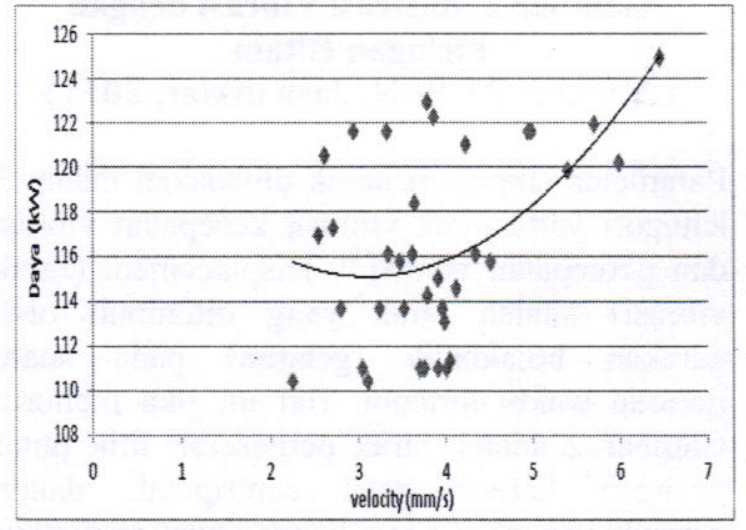

Gambar 7. Dampak Vibrasi Mekanik terhadap Konsumsi Listrik pada Titik MOH 


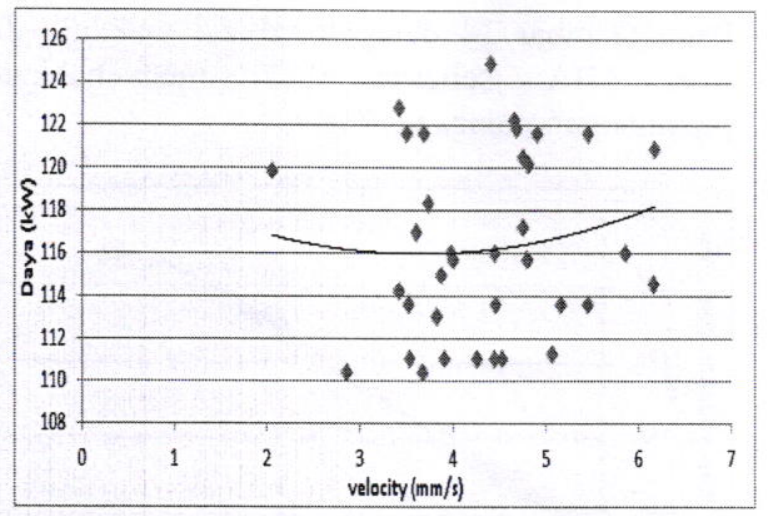

Gambar 8. Dampak Vibrasi Mekanik terhadap Konsumsi Listrik pada Titik MOV

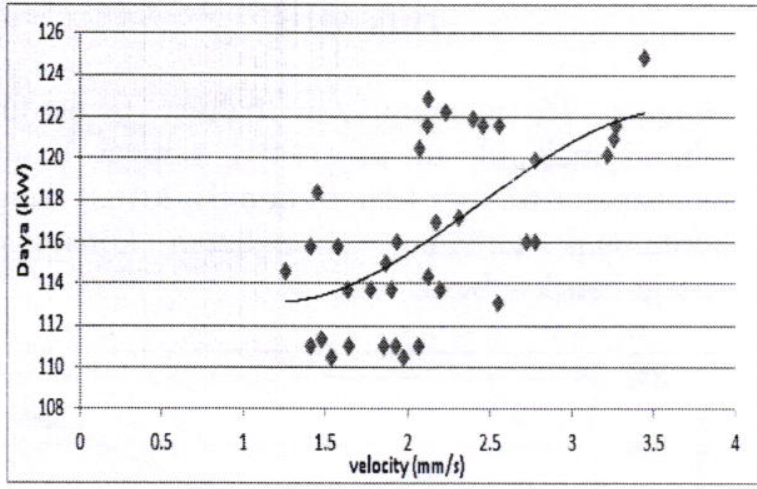

Gambar 9. Dampak Vibrasi Mekanik terhadap Konsumsi Listrik pada Titik MIA

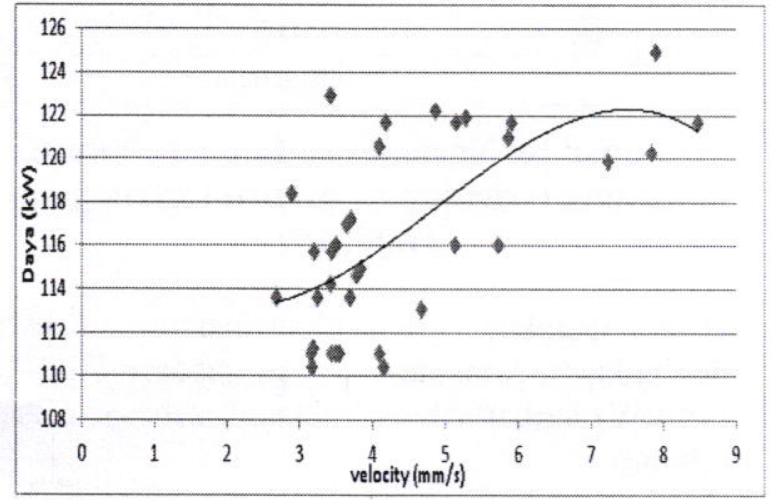

Gambar 10. Dampak Vibrasi Mekanik terhadap Konsumsi Listrik pada Titik MIH

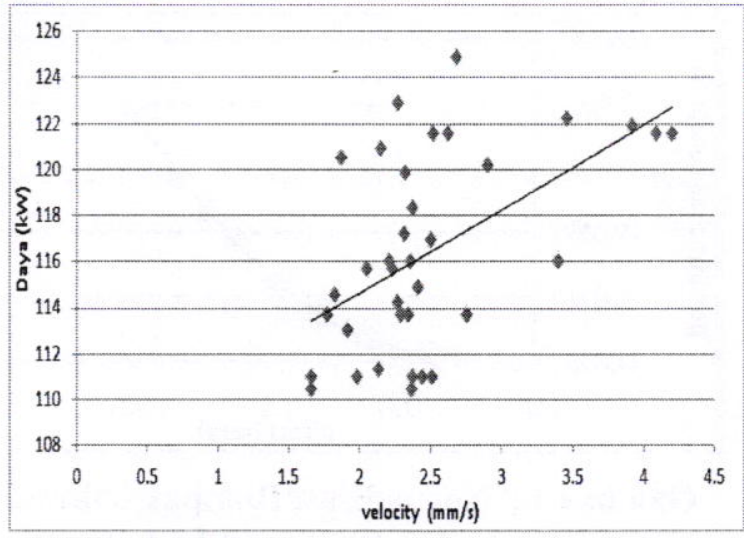

Gambar 11. Dampak Vibrasi Mekanik terhadap Konsumsi Listrik pada Titik MIV

Berdasarkan gambaran pada profil dampak vibrasi mekanik terhadap konsumsi daya listrik menunjukkan bahwa terjadi kecenderungan peningkatan konsums energi listrik akibat meningkatnya vibrasi mekanik. Sedangkan berdasarkan standard ISO 10816 besaran kecepatan vibrasi mekanik yang diperkenankan berkisar 1,25 kali kondisi normal. Disisi lain tingkat kecepatan vibrasi untuk kapasitas motor ukuran medium (15-300 $\mathrm{kW})$ dengan menggunakan kopling fleksibel, sebesar 7,1 $\mathrm{mm} / \mathrm{s}$ dikategorikan pada kondisi vibrasi penyebab kerusakan. Gambaran operasi motor ini menunjukkan bahwa vibrasi mekanik tertinggi pada $\mathrm{MOH}$ dan $\mathrm{MIH}$ yakni dalam kondisi C (short term operation) diperlukan perbaikan.

Dampak vibrasi mekanik berpeluang mengurangi umur mesin dan meningkatkan konsumsi energi listrik ${ }^{[1]}$. Dengan melakukan normalisasi data pengukuran konsumsi energi listrik dan vibrasi mekanik, maka dapat diformulasikan pendekatan sebagaimana tercermin pada Gambar 3. Secara detil dampak vibrasi mekanik terhadap persentasi kenaikan konsumsi energi untuk setiap pengukuran diperlihatkan pada Gambar 12 sampai dengan Gambar 17. 


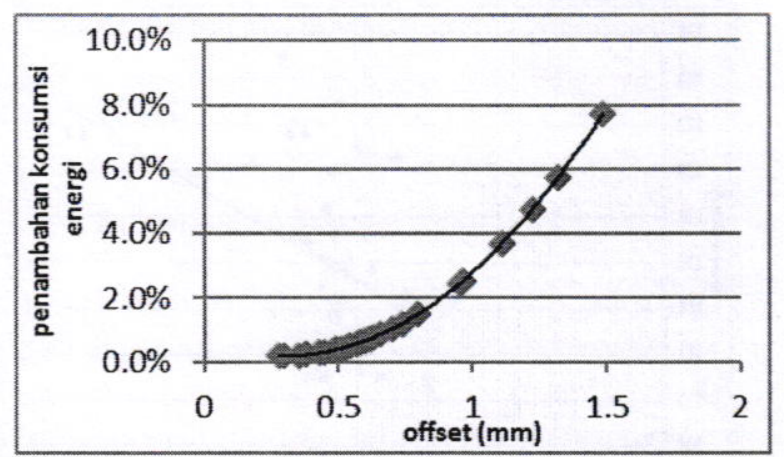

Gambar 12. Normalisasi Dampak Vibrasi Mekanik terhadap Konsumsi Listrik pada Titik MOH

Dari Gambar 12 pada offset tertinggi sebesar $1,48 \mathrm{~mm}$ (titik kritis $1,5 \mathrm{~mm}$ ) mengakibatkan terjadi peningkatan konsumsi energi sebesar $7,7 \%$.

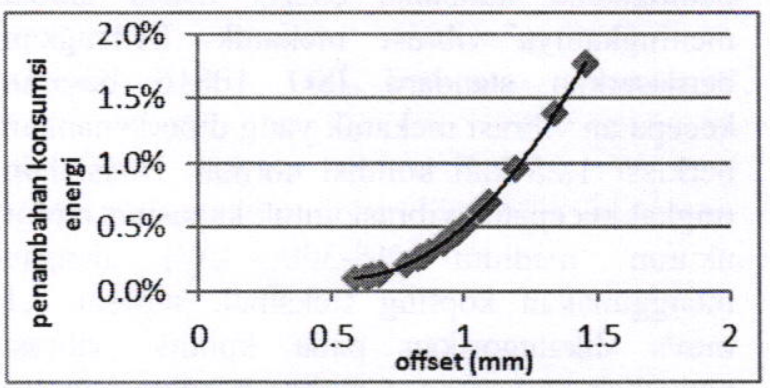

Gambar 13. Normalisasi Dampak Vibrasi Mekanik terhadap Konsumsi Listrik pada Titik MOV

Gambar 13 dengan offset tertinggi sebesar 1,45 $\mathrm{mm}$, didapat peningkatan konsumsi energi listrik relatif kecil sebesar $1,8 \%$, hal ini menunjukkan bahwa dampaknya relatif kecil terhadap peningkatan konsumsi energi pada titik MOV.

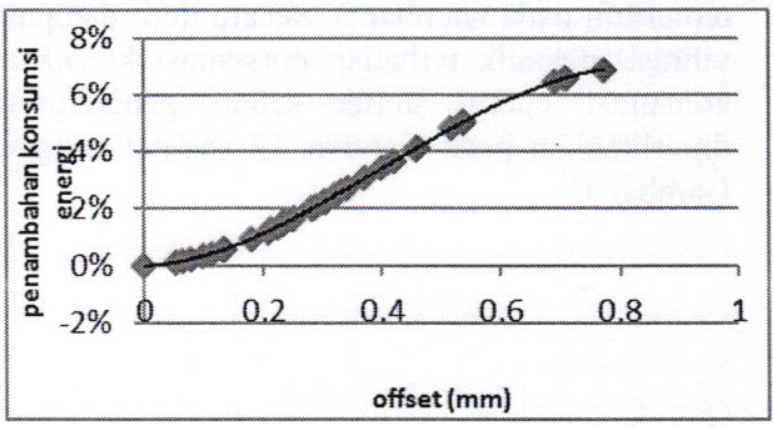

Gambar 14. Normalisasi Dampak Vibrasi Mekanik terhadap Konsumsi Listrik pada Titik MIA
Pada Gambar 14 dampak vibrasi mekanik di titik MIA sebesar 0,77 menyebabkan peningkatan mencapai $7 \%$.

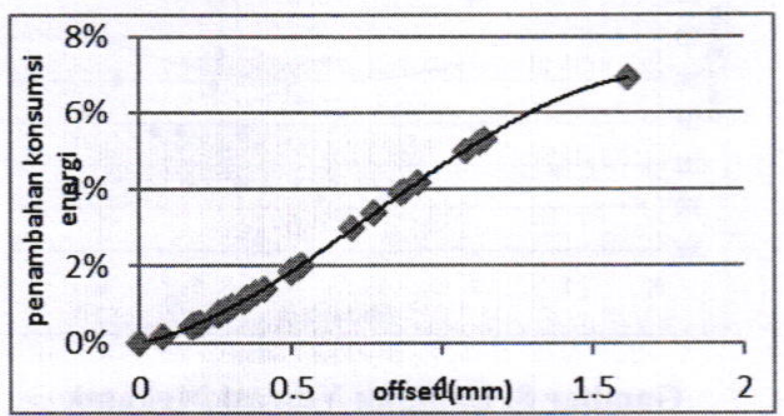

Gambar 15. Normalisasi Dampak Vibrasi Mekanik terhadap Konsumsi Listrik pada Titik MIH

Gambar 15 menunjukkan bahwa pengaruh vibrasi mekanik di titik MIH samgat besar mencapai 1,61 mm (dalam kondisi kritis) yang berdampak terhadap peningkatan konsumsi energi listrik sebesar 6,92\%.

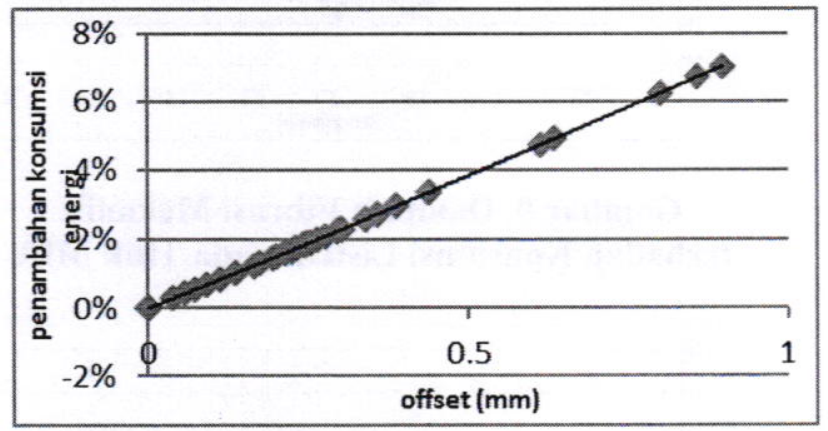

Gambar 16. Normalisasi Dampak Vibrasi Mekanik terhadap Konsumsi Listrik pada Titik MIV

Dari Gambar 16 diperlihatkan bahwa peningkatan konsumsi energi sebesar 7,05\% $(14 \mathrm{~kW})$ akibat vibrasi mekanik sebesar offset $0,9 \mathrm{~mm}$.

Dampak vibrasi mekanik pada motor listrik akan sangat berpengaruh terhdap kinerja pompa, terutama bila vibrasi tinggi pada titik MIV dan MIH. Tingginya vibrasi mekanik pada $\mathrm{MOH}$ dan $\mathrm{MOV}$ menunjukkan bahwa perlunya perawatan dan perbaikan segera dilakukan.

Sejalan dengan dampaknya tehadap konsumsi energi listrik, umur mesin akan terdipresiasi akibat vibrasi mekanik (Gambar 17). 


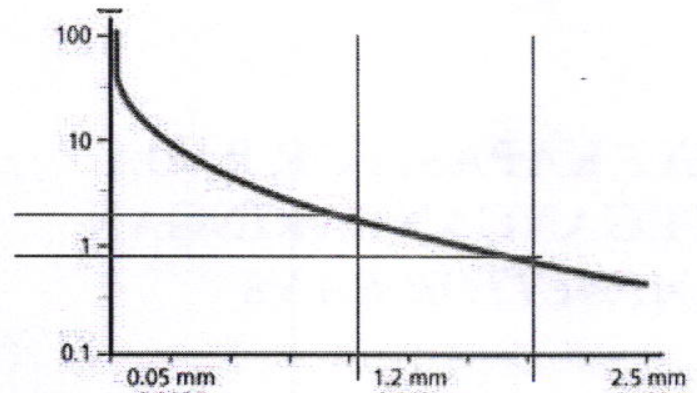

Gambar 17. Normalisasi Dampak Vibrasi Mekanik terhadap Konsumsi Listrik pada Titik MIV

Gambar 17 menunjukkan bahwa vibrasi mekanik pada kisaran offset maksimum sebesar $0,8 \mathrm{~mm}$ sampai dengan $1,61 \mathrm{~mm}$ menyebabkan mur mesin terdipresiasi dengan kisaran $0,8 \%-1,2 \%$ dari umur normalnya.

\section{KESIMPULAN}

Kajian dampak vibrasi mekanik tehadap konsumsi energi listrik pada CWP Unit I PLTA Cirata menghasilkan beberapa temuan pokok sebagai berikut:

1. Operasi motor listrik pada CWP unit I menunjukkan bahwa motor hanya diperkenankan beroperasi dalam waktu pendek, kategori C (ISO 10816-3).

2. Dampak vibrasi mekanik pada titik $\mathrm{MOH}$, MOV dan MIH berada pada kondisi kritis yaitu pada kondisi offset di atas $1,5 \mathrm{~mm}$. Sehingga motor beroperasi dengan boros energi yang mencapai $6,92 \%$

3. Umur motor listrik CWP, bila tidak dilakukan perawatan, akan terdepresiasi sekitar $0,8 \%$ $1,2 \%$ dari umur normalnya. Hal tersebut akibat terjadi vibrasi mekanik pada kisaran offset maksimum sebesar $0,8 \mathrm{~mm}$ sampai dengan 1,61 $\mathrm{mm}$.

\section{DAFTAR PUSTAKA}

PRÜFTECHNIK, Effect of Misalignment, 2013.

(http://www.pruftechnik.com/en/ali gnment-

systems/alignmentknowledge/effect s-of-misalignment.html diakses tanggal 10 Mei 2013)

Laporan PT PLN Unit Pendidikan dan Pelatihan Suralaya, 2013. (http://www.scribd.com/doc/67018 008/TEORI-VIBRASI-OK diakses tanggal 5 Mei 2013)

Internasional Standart ISO 10816-3, 2003, Mechanical vibration measurements on non rotating parts First edition.

Wahdiat Deddy, 2005, Basic Vibration Analysis Course prensentation PT. Tiara Vibrasindo Pratama.

Ulfiana Andi, 2010, Analisis Pengaruh Misaligment Terhadap Vibrasi dan Kinerja Motor Induksi Depok, Universitas Indonesia. 